\title{
DETERMINACIÓN DEL EFECTO CICATRIZANTE DE Piper aduncum (MATICO) EN FIBROBLASTOS HUMANOS
}

\author{
Karen Paco ${ }^{1, a}$, Luis Alberto Ponce-Soto ${ }^{2, b}$, Marco Lopez-Ilasaca ${ }^{3, c}$, José L. Aguilar ${ }^{4, d}$
}

\begin{abstract}
RESUMEN
Objetivos. Evaluar el efecto cicatrizante del extracto hidroetanólico de Piper aduncum, en una línea celular de fibroblastos Dermales Adultos Humanos (hDFa). Materiales y métodos. El extracto se obtuvo mediante extracción sólido-líquido, fue concentrado y liofilizado. Se purificaron las proteínas del extracto mediante cromatografía líquida de alta eficacia de fase reversa (RP-HPLC); las proteínas fueron identificadas por espectrometría de masas en tándem de péptidos trípticos y se analizaron por MALDI-TOF-TOF en un espectrómetro de masa ABSciex4800. Los valores de concentración efectiva media $\left(\mathrm{EC}_{50}\right)$, concentración inhibitoria media $\left(\mathrm{IC}_{50}\right)$, y el porcentaje de proliferación celular; fueron determinados por ensayos con sales de tetrazolio (MTT) . La migración celular se evaluó mediante la "técnica de rayado". Se analizó la expresión de factores de crecimiento mediante el ensayo de reacción en cadena de la polimerasa con transcriptasa reversa a tiempo real (RT- qPCR). Resultados. La línea hDFa evidenció un IC ${ }_{50}$ de $200 \mu \mathrm{g} / \mathrm{mL}$ con el extracto, el valor de $E_{50}$ fue $103,5 \mu \mathrm{g} / \mathrm{mL}$. En el ensayo de proliferación, la proteína K2; mostró mayor actividad en la proliferación respecto de otros tratamientos $(1 \mu \mathrm{g} / \mathrm{mL}$ ). En el ensayo de migración de fibroblastos, la proteína $\mathrm{K} 2$ mostró mayor actividad (50 $\mu \mathrm{g} / \mathrm{mL}$ ). La expresión relativa del factor de crecimiento derivado de plaquetas (PDGF) se incrementó 8,6 veces respecto al control, en presencia de la proteína K2. Conclusiones. El extracto hidroetanólico, de Piper aduncum, así como las proteínas que contiene, incrementaron la proliferación y migración de fibroblastos dermales humanos (hDFa); así mismo, aumentaron la expresión de factores de crecimiento que intervienen en el proceso de cicatrización.
\end{abstract}

Palabras clave: Cicatrización de heridas; Péptidos; Piper; Proliferación de la célula; Movimiento celular; Espectrometría de masas (fuente: DeCS BIREME).

\section{DETERMINATION OF THE HEALING EFFECT OF Piper aduncum (SPIKED PEPPER OR MATICO) ON HUMAN FIBROBLASTS}

\begin{abstract}
Objectives. To evaluate the healing effect of a Piper aduncum ethanol-water extract on an adult human dermal fibroblast cell line (hDFa). Materials and Methods. After obtaining the extract via solid-liquid extraction, concentration, and lyophilization, extract proteins were purified using reverse phase high-performance liquid chromatography, identified using tandem mass spectrometry of tryptic peptides, and analyzed using MALDI-TOF-TOF on an ABSciex4800 mass spectrometer. Half maximum effective concentration values (EC50), half maximum inhibiting concentration (IC50), and percentages of cell proliferation were determined using tetrazolium salt assays. Cell migration was evaluated using a "scratch assay". Growth factor expression in cells was analyzed via quantitative real-time reverse transcription polymerase chain reaction. Results. Against the hDFa cell line, the extract had an IC50 of $200 \mu \mathrm{g} / \mathrm{mL}$ and EC50 of 103.5 $\mu \mathrm{g} / \mathrm{mL}$. In the proliferation assay, protein $\mathrm{K} 2$ (obtained from the extract) exhibited increased proliferative activity relative to other treatments $(1 \mu \mathrm{g} / \mathrm{mL})$; this agent also exhibited increased activity $(50 \mu \mathrm{g} / \mathrm{mL})$ in the fibroblast migration assay. Furthermore, the relative expression of platelet-derived growth factor increased by 8.6-fold in the presence of K2 protein relative to the control. Conclusions. The hydroethanolic extract of Piper aduncum and its component proteins increased the proliferation and migration of hDFa and increased the expression of growth factors involved in the healing process.
\end{abstract}

Key words: Wound healing; Peptides; Piper; Cell proliferation; Cell movement; Mass spectrometry (Source: MeSH NLM).

\footnotetext{
Facultad de Ciencias Farmacéuticas Bioquímicas y Biotecnológicas, Universidad Católica de Santa María. Arequipa, Perú.

Departamento de Bioquímica, Instituto de Biología, Universidad Estadual de Campinas. Campinas SP, Brasil.

Departamento de Medicina, Harvard Medical School, Boston, Massachusetts

Laboratorio de Inmunología, Departamento de Ciencias Celulares y Moleculares, Facultad de Ciencias, Universidad Peruana Cayetano Heredia. Lima, Perú.

a Bachiller en Ingeniería Biotecnológica; ${ }^{b}$ doctor en Biología Funcional y Molecular-Química de Proteínas; ${ }^{\mathrm{c}}$ doctor en Medicina; ${ }^{\mathrm{d}}$ magíster en Medicina Recibido: 14/08/2015 Aprobado: 01/06/2016
} 


\section{INTRODUCCIÓN}

Las heridas crónicas y no cicatrizadas tienen una elevada incidencia en la población a nivel mundial (1). La cicatrización es un proceso de restauración que consiste en la superposición de eventos que involucran la respuesta inflamatoria, regeneración de la epidermis, contracción de la herida y finalmente la formación del tejido conectivo y remodelación. El tratamiento apropiado acelera el proceso de cicatrización y previene la infección y cronicidad de la herida ${ }^{(1,2)}$.

Cada etapa del proceso de cicatrización está orientada por la expresión de proteínas que controlan los patrones del ciclo celular. El éxito del proceso depende de factores de crecimiento, los que son polipéptidos biológicamente activos que actúan para alterar el crecimiento, la diferenciación y el metabolismo de una célula diana. Destacan por su actividad en el proceso de cicatrización el factor de crecimiento derivado de plaquetas (PDGF) que se libera en la fase inflamatoria, el factor de crecimiento de fibroblastos (FGF) y el factor de crecimiento epidermal (EGF), los que intervienen en la fase de proliferación celular ${ }^{(3,4)}$.

A través de los años, varios productos vegetales se han utilizado en el tratamiento de heridas; por ejemplo, existen extractos de hierbas que promueven la coagulación de la sangre, combaten la infección y aceleran su curación. El valor medicinal de estas plantas radica en constituyentes fitoquímicos bioactivos. Estos componentes incluyen diversas familias químicas como alcaloides, aceites esenciales, flavonoides, taninos, terpenoides, saponinas, y compuestos fenólicos. Además de estos componentes, las plantas son las principales fuentes de péptidos, los cuales son moléculas de proteínas de menos de $10 \mathrm{kDa}$; que pueden existir de forma natural o ser derivados de secuencias de proteínas nativas ${ }^{(5,6)}$. En los últimos años, una amplia evidencia científica ha previsto la existencia de péptidos activos biológicos y proteínas derivadas de plantas que podrian tener efectos beneficiosos sobre la salud humana ${ }^{(7)}$.

Piper aduncum, matico, se distribuye a lo largo del Amazonas, muchas de las tribus locales utilizan las hojas de matico como cicatrizante. Existen estudios que indican que los flavonoides, alcaloides,saponinas, taninos, esteroides y aceites esenciales estarían implicados en esta función $(8,9,10)$.

En este trabajo evaluamos el efecto cicatrizante del extracto hidroetanólico y péptidos bioactivos purificados mediante cromatografía líquida de alta eficacia de fase reversa (RP-HPLC) de Piper aduncum en la línea celular de Fibroblastos Dermales Adultos Humanos (hDFa). Debido a que el proceso de cicatrización involucra diversas etapas; se evaluó la expresión de algunos factores de crecimiento que intervienen en cada una de ellas: EGF, FGF y PDGF.

\section{MATERIALES Y MÉTODOS}

\section{OBTENCIÓN DE EXTRACTO HIDROETANÓLICO LIOFILIZADO DE Piper aduncum}

Las hojas de Piper aduncum, matico, fueron colectadas de las ciudad de Arequipa y certificadas por el Herbario Arequipense HUSA de la Universidad Nacional de San Agustín. Las hojas fueron llevadas a sequedad, para luego ser pulverizadas en un mortero. Se pesó $50 \mathrm{~g}$ de la muestra pulverizada y se realizó la extracción sólidolíquido en un equipo Soxhlet, durante $6 \mathrm{~h}$. Se utilizó una mezcla etanol-agua 70/30. Finalmente, se eliminó el etanol mediante con un rotavapor. El extracto fue liofilizado y almacenado a $4^{\circ} \mathrm{C}$.

\section{CULTIVO DE LÍNEA CELULAR hDFa}

La línea celular hDFa fue obtenida de Life Technologies (Carlsbad, CA), y cultivada en placas con medio Dulbecco's Modified Eagle's Medium (DMEM), suplementado con $10 \%$ de suero bovino fetal (FBS) y una mezcla de antibióticos y antimicóticos (estreptomicina $10 \mathrm{mg}$, penicilina 10000 unidades, anfotericina B 0,23 $\mathrm{mg}$ ). El cultivo se mantuvo a $37^{\circ} \mathrm{C}$ en una atmósfera de $5 \%$ de $\mathrm{CO}_{2}$ Se utilizó el método de azul de tripán para evaluar viabilidad celular.

\section{PURIFICACIÓN DE PROTEÍNAS MEDIANTE CROMATOGRAFÍA LIQUUIDA DE ALTA EFICACIA DE FASE REVERSA (RP-HPLC)}

Las fracciones proteicas fueron purificadas en una columna u-Bondapack C18 $(0,78 \times 30 \mathrm{~cm})$ preparativa, previamente equilibrada con ácido trifluoracético $0,1 \%$ $\mathrm{pH}=3,5$ (tampón A) acoplada a un sistema de HPLC de fase reversa. El sistema cromatográfico usado es de HPLC-PDA 991 (waters), equipado con dos bombas (waters) modelo 510/B, un inyector automático de muestras U6K con un lazo o asa de $2,0 \mathrm{~mL}$ de capacidad. Inicialmente, la elusión de las muestras fue realizada a través de un gradiente lineal con acetonitrilo $66 \%$ (tampón B), que fue modificado para la optimización de la purificación de las fracciones. Las fracciones fueron monitoreadas a $280 \mathrm{~nm}{ }^{(11)}$.

\section{IDENTIFICACIÓN DE PROTEÍNAS POR ESPECTROMETRÍA DE MASAS EN TÁNDEM DE PÉPTIDOS TRÍPTICOS}

Los picos de proteínas provenientes de la purificación vía RP-HPLC, se sometieron a reducción (ditiotreitol $10 \mathrm{mM}$ ), alquilación (yodoacetamida $50 \mathrm{mM}$ ) y se analizaron por MALDI-TOF-TOF en un espectrómetro de masa AB Sciex 4800 (Applied Biosystems). Cada proteína se mezcló con 
un volumen igual de ácido $\alpha$-ciano-hidroxicinámico saturado (en $50 \%$ de acetonitrilo, $0,1 \%$ ácido trifluoroacético), en una placa de 384 pocillos Opti-TOF, se secaron y se analizaron en el modo reflector positivo. Los espectros fueron adquiridos utilizando 1500 disparos y una intensidad del láser de 3000. Se seleccionaron de forma automática los diez iones precursores más intensos, y sus espectros de fragmentación TOF-TOF fueron adquiridos utilizando 500 disparos a una intensidad del láser de 3900. La calibración externa en cada ejecución se realizó con normas CalMix® (ABSciex) avistados en la misma placa. Para la identificación de proteínas en espectros resultantes se realizaron búsquedas en la base de datos UniProt/ SwissProt usando ProteinPilot $®$ v.4 y el algoritmo Paragon $®$ (ABSciex) con $\geq 95 \%$ de confianza, o interpretada de forma manual. Las secuencias de péptidos con puntajes más bajos de confianza se buscaron manualmente utilizando BLAST (http://blast.ncbi.nlm.nih.gov) para la similitud de proteínas y la asignación de la familia de proteínas ${ }^{(12)}$.

\section{ENSAYOS BASADOS EN SALES DE TETRAZOLIO (MTT) EVALUACIÓN DEL EXTRACTO Y SUS FRACCIONES PROTEICAS, EN LA PROLIFERACIÓN CELULAR}

Las células hDFa fueron cultivadas en placas de 96 pozos; con una densidad de $2 \times 10^{4}$ células por pozo. El extracto hidroetanólico liofilizado se disolvió en dimetilsulfoxido (DMSO); (50, 100, 200, $250 \mu \mathrm{g} / \mathrm{mL}$ ) y fue agregado al cultivo. Las proteínas purificadas $\mathrm{K} 1$ y $\mathrm{K} 2$ fueron disueltas en agua y añadidas al cultivo (1, 10, y $50 \mu \mathrm{g} / \mathrm{mL})$.

Para evaluar la proliferación, se disolvió MTT en tampón de fosfatos (PBS) a una concentración de $5 \mathrm{mg} / \mathrm{mL}$. El cultivo fue incubado a diferentes tiempos (24, 48 y 72 h) a $37{ }^{\circ} \mathrm{C}$ en una atmósfera de $5 \%$ de $\mathrm{CO}_{2}$. Una vez terminado el tiempo de incubación se adicionó $20 \mu \mathrm{L}$ de la solución de MTT y se incubó en oscuridad por $4 \mathrm{~h}$ a $37^{\circ} \mathrm{C}$. Finalmente, se eliminó el MTT, se leyó la absorbancia a $570 \mathrm{~nm}$ en un espectrofotómetro marca Thermo Spectronic modelo Genesys 10 y se determinó el porcentaje de proliferación. Se construyeron las curvas para determinar los valores de Concentración inhibitoria media $\left(\mathrm{IC}_{50}\right)$ y Concentración efectiva media $\left(\mathrm{EC}_{50}\right)^{(13)}$.

\section{ENSAYO PARA EVALUACIÓN DE MIGRACIÓN CELULAR. TÉCNICA DEL RAYADO}

Las células se cultivaron hasta confluencia y se realizó una "herida", introducida por el raspado con una punta de pipeta. Las células en el borde de la herida polarizan y migran hacia el espacio de la herida.

El cultivo fue tratado con diferentes concentraciones del extracto hidroetanólico (50, 100 y $200 \mu \mathrm{g} / \mathrm{mL})$; así como diferentes concentraciones de las proteínas $\mathrm{K} 1$ y K2 (10 y $50 \mu \mathrm{g} / \mathrm{mL}$ ). Se trabajó por triplicado para cada tratamiento. Este ensayo se llevó a cabo en placas de seis pozos, en donde se sembraron los fibroblastos, y dejaron crecer hasta confluencia, se aplicaron los diferentes tratamientos y, finalmente, se cuantificó la migración de los fibroblastos después de 24,48 y 72 h con el software WinScratch de Ibidi. Se evaluó el porcentaje de migración de fibroblastos hacia el centro de la herida ${ }^{(14,15)}$.

\section{EXTRACCIÓN DEL ARN DE FIBROBLASTOS Y ANÁLISIS DE EXPRESIÓN DE ADN COMPLEMENTARIO (ADNc) MEDIANTE RT- qPCR}

El cultivo celular (hDFa) fue tratado con diferentes concentraciones del extracto hidroetanólico (50, 100 y $200 \mu \mathrm{g} / \mathrm{mL}$ ), y diferentes concentraciones de las proteínas K1 y K2 (10 y $50 \mu \mathrm{g} / \mathrm{mL}$ ). Se trabajó por triplicado para cada tratamiento. Este ensayo se llevó a cabo en placas de doce pozos, en donde se sembraron los fibroblastos, y se dejaron crecer hasta confluencia, se aplicaron los diferentes tratamientos y se dejó incubar en diferentes tiempos ( 1 y $3 \mathrm{~h}$ ). Finalmente, se extrajo el ARN total del cultivo, mediante el método de trizol ${ }^{(13)}$. Se utilizó el reactivo RNAzolRt. EI ARN obtenido fue transformado a ADNc utilizando el kit Super Script III Reverse Transcriptase de Life Technologies (Carlsbad, CA); se utilizó el Equipo Eppendorf Mastercycler realplex. Para evaluar la pureza de ARN; se consideró la relación $260 / 280$. Luego, se procedió a amplificar el ADNc utilizando primers para los genes EGF, FGF Y PDGF, los cuales fueron obtenidos utilizando el software "Primer3". Los primer utilizados fueron:

Gen EGF: forward: 5CAATGCAACCAACTTCATGG3, reverse: AAGCTTCGCTCCATTACCTG3, Gen FGF: forward: 5CTCTTTCAGCATTCACAC3, reverse: 5TCCCCTAACACAACTTAC3 Gen PDGF: forward:5'CACACCTCCTCGCTGTAGTATTTA3, reverse: 5'GTTATCGGTGTAAATGTCATCCAA3', Gen GAPDH: forward: 5'GAAGGTGAAGGTCGGAGTC3, reverse: 5'GAAGATGGTGATGGGATT'3.

Se utilizó gliceraldehido 3-fosfato deshidrogenasa; GAPDH como gen de referencia. La amplificación se realizó utilizando $\mathrm{RT}$-qPCR, para la cuantificación se utilizó el método $2^{\Delta \Delta C t}$, de cuantificación relativa ${ }^{(16,17)}$.

\section{ANÁLISIS ESTADÍSTICO}

Los valores de $\mathrm{EC}_{50}, \mathrm{IC}_{50}$, porcentaje de proliferación celular; porcentaje de migración y expresión relativa de los factores de crecimiento en el cultivo celular; fueron comparados utilizando la prueba estadística ANOVA de una cola, para tal objetivo se utilizó el software GrapdPad Prism 6.

\section{RESULTADOS}

\section{EXTRACCIÓN DE PROTEÍNAS MEDIANTE RP-HPLC}

Se obtuvieron cinco picos de proteínas que fueron liofilizadas y cuantificadas vía Bradford; se obtuvo 0,3 $\mathrm{mg} / \mathrm{mL}$ de proteína (Figura 1). 


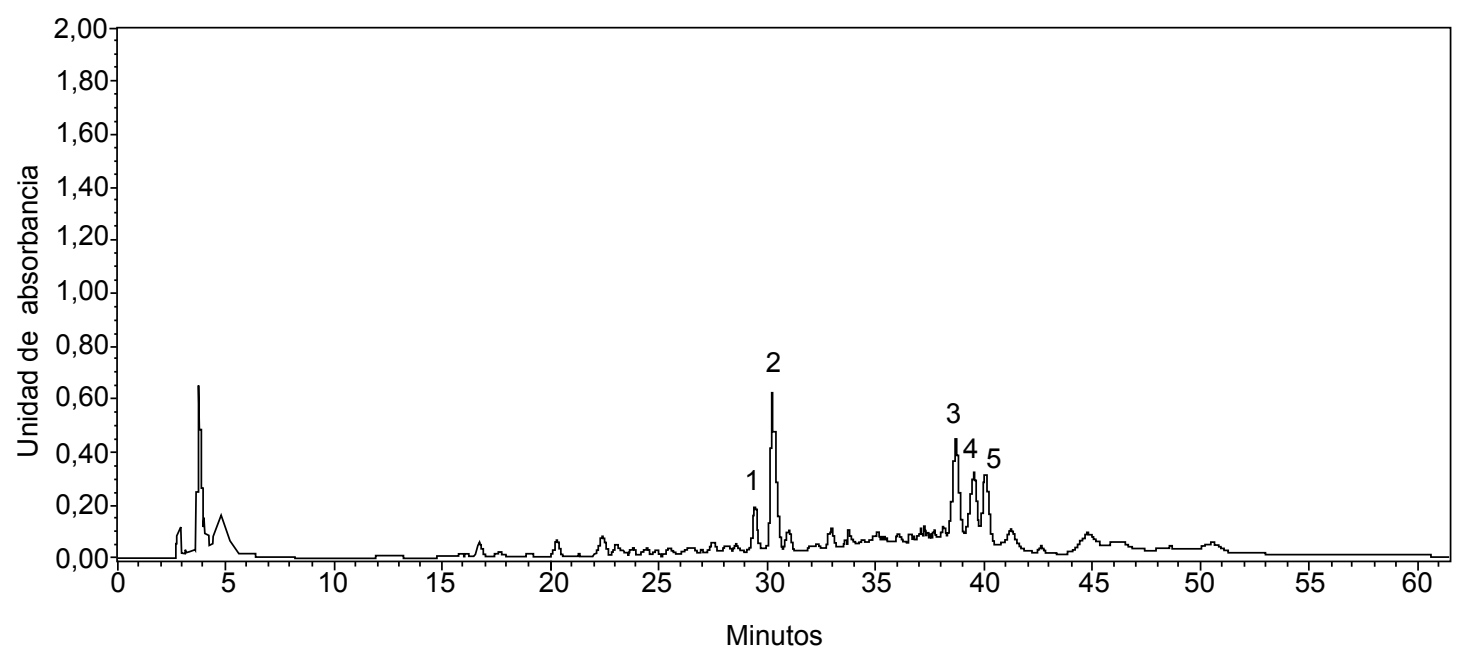

Figura 1. Cromatograma RP-HPLC. Cinco picos de elución de diferentes proteínas.

Los picos de proteínas obtenidos; fueron denominados arbitrariamente: $\mathrm{K} 1, \mathrm{~K} 2, \mathrm{~K} 3, \mathrm{~K} 4$ y K5; para los posteriores ensayos.

\section{IDENTIFICACIÓN DE PROTEÍNAS POR ESPECTROMETRÍA DE MASAS EN TÁNDEM DE PÉPTIDOS TRÍPTICOS}

Se obtuvieron las secuencias de aminoácidos de las porciones $n$-terminales de las cinco proteínas obtenidas por RP-HPLC:

$\begin{array}{ll}\text { K1 } & \text { EPLLDSEGELVENGGTYYIVPA } \\ \text { K2 } & \text { VLVDGNGEPLVNGGSAYYILS } \\ \text { K3 } & \text { KELLDSDGDILRNGGTYYILPALR } \\ \text { K4 } & \text { VLLDGNGEVVQNGGTYYLL } \\ \text { K5 } & \text { QPLVDLEGNLVENGGTYYLLP }\end{array}$

ANÁLISIS DE LAS SECUENCIAS N-TERMINAL MEDIANTE BLAST (ALINEAMIENTO DE SECUENCIAS DE TIPO LOCAL)

Se realizó el análisis de las secuencias $N$-terminales de las proteínas obtenidas por RP-HPLC, utilizando el BLAST, contra las proteínas no redundantes $(\mathrm{nr})$ de la base de datos. Se evaluaron los e-value así como los porcentajes de identidad.

Proteína K1: se encontró la proteína homóloga: Inhibidor de tripsina de Psophocarous tetragonolobus. (Trypsin inhibitor 19, AltName: Full=WT-1 Psophocarpus tetragonolobus, sequence ID P10821.1, identidad: 86\%, e-value: 2e-08).

Proteína K2: se encontró la proteína homóloga: cadena alfa del Inhibidor de tripsina tipo Kunitz (Beta vulgaris vulgaris, sequence ID:XP_010693620, identidad: $78 \%$, e-value : 0.58).

Proteína K3: se encontró la proteína homóloga: Inhibidor de tripsina de Enterolobium contortisiliquum
(RecName: Full=Trypsin inhibitor beta chain Enterolobium contortisiliquum, identidad: $100 \%$, e-value: 1e-16).

Proteína K4: se encontró la proteína homóloga: inhibidor de tripsina DE-3 de Erythrina corallodendron, (sequence ID: P68170.1, identidad: $100 \%$, e-value: 1e-12).

Proteína K5: se encontró la proteína homóloga: Inhibidor de quimotripsina de Erythrina variegata, (sequence ID. P34952.1, identidad: $100 \%$, e-value: 1e-13).

Luego del análisis y búsqueda de secuencias homólogas; mediante alineamiento local; se encontró un dominio conservado en común para las cinco proteínas purificadas del extracto. Este dominio pertenece a la superfamilia STI (inhibidores de tripsina), los que son inhibidores de proteasas, debido a que se unen con alta afinidad a sus sitios activos. El plegamiento del dominio es común en interleuquinas y factores de crecimiento de fibroblastos, plegamiento tipo "trébol". Esta familia de inhibidores de proteasas tiene una estructura en común denominada Kunitz.

Finalmente las proteínas $\mathrm{K} 3$ y $\mathrm{K} 5$; tienen otro dominio en común denominado pfam00197, el que también pertenece al grupo de inhibidores de proteasas y tripsina.

\section{EVALUACIÓN DEL EXTRACTO HIDROETANÓLICO LIOFILIZADO Y SUS FRACCIONES PROTEICAS, SOBRE LA PROLIFERACIÓN CELULAR}

El cultivo celular fue tratado con diferentes concentraciones del extracto $(10,50,100,200$ y 250 $\mu \mathrm{g} / \mathrm{mL}$ ); se observó un aumento significativo en el porcentaje de proliferación celular después de 24, 48 y 72 horas (h) de aplicar el tratamiento (Figura 2A). Las proteínas $\mathrm{K} 1$ y $\mathrm{K} 2$ también fueron añadidas al cultivo (1, $10,50 \mu \mathrm{g} / \mathrm{mL}$ ), se observó un incremento en el porcentaje de proliferación después de 24,48 y 72 h de aplicado el 

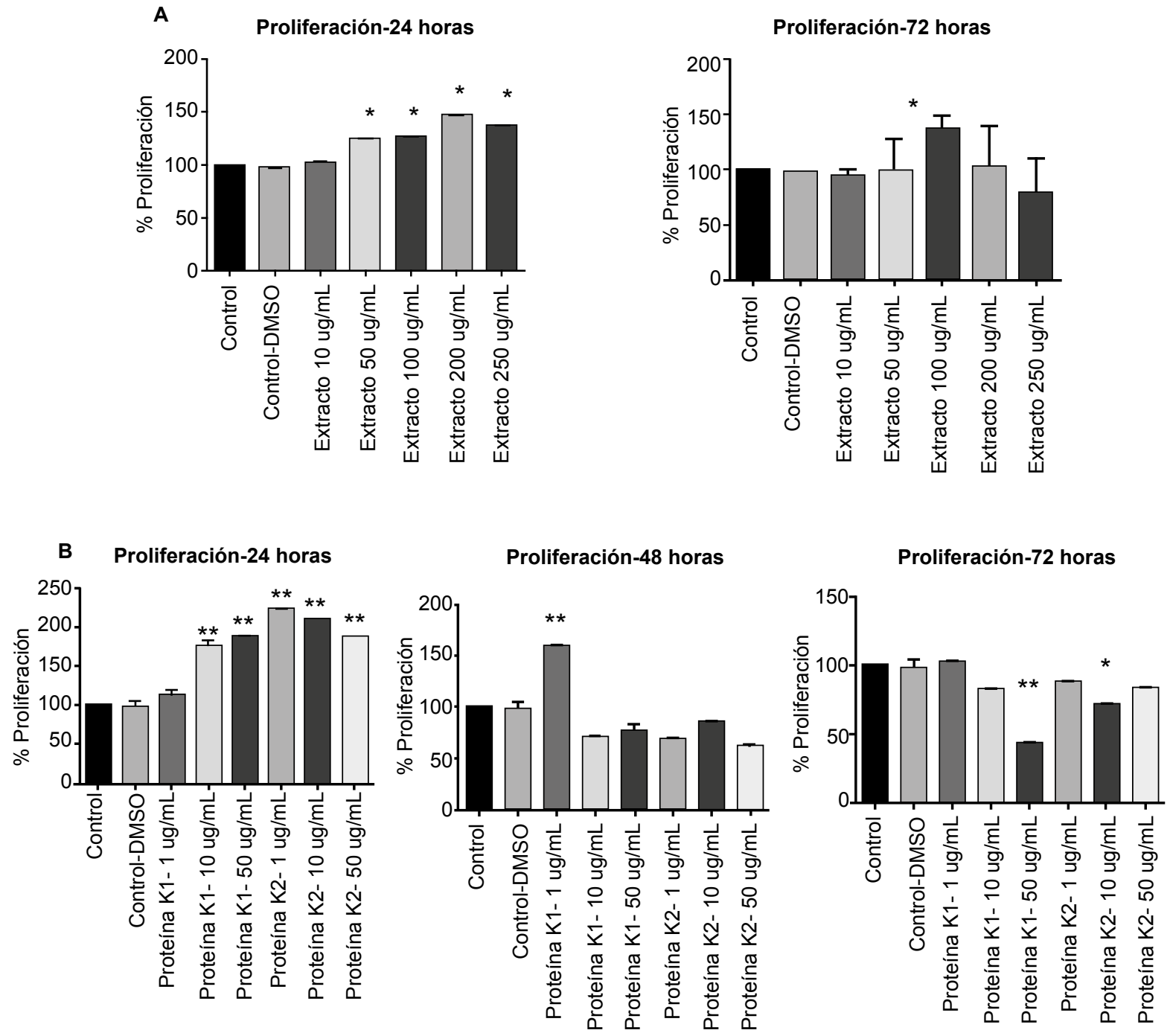

Figura 2. A. Porcentaje de proliferación de fibroblastos a las 24 y 72 horas (h) después de aplicar el extracto hidroetanólico de Piper aduncum a diferentes concentraciones. B. Porcentaje de proliferación de fibroblastos a las 24,48 y $72 \mathrm{~h}$ después de aplicar el tratamiento con las proteínas K1 y K2 ${ }^{*} p<0,05,{ }^{* *} p<0,01$ comparadas con el control negativo, sin tratamiento.

tratamiento (Figura 2B). Las muestras fueron evaluadas por triplicado y se trabajó con dos controles negativos; uno de ellos sin tratamiento; y el otro fue tratado con DMSO.

\section{DETERMINACIÓN DE EC 50}

Para encontrar el valor de la concentración efectiva media $\left(\mathrm{EC}_{50}\right)$, se determinó el porcentaje de proliferación utilizando las concentraciones de 50,100 y $200 \mu \mathrm{g} /$ $\mathrm{mL}$ del extracto hidroetanólico de Piper aduncum, y se obtuvo el $\mathrm{EC}_{50}$ después de 24 y $48 \mathrm{~h}$ de aplicar el tratamiento (Figura 3).

El software GraphPad Prism 6 permitió determinar el valor de $\mathrm{EC}_{50}$ a las $24 \mathrm{~h}$ después de aplicados los tratamientos y se obtuvo el valor de $103,5 \mu \mathrm{g} / \mathrm{mL}$. El valor de $\mathrm{EC}_{50}$ a las $48 \mathrm{~h}$ fue de $39,54 \mu \mathrm{g} / \mathrm{mL}$.

\section{DETERMINACIÓN DE IC ${ }_{50}$}

Para determinar la concentración inhibitoria media $\left(\mathrm{IC}_{50}\right)$ se obtuvo el porcentaje de proliferación después de 72 $\mathrm{h}$ de aplicar el tratamiento con el extracto hidroetanólico $(50,100$ y $250 \mu \mathrm{g} / \mathrm{mL})$. El valor de $\mathrm{IC}_{50}$ fue de $200 \mu \mathrm{g} / \mathrm{mL}$.

\section{DETERMINACIÓN DE MIGRACIÓN DE FIBROBLASTOS. TÉCNICA RAYADO "SCRATCH"}

El cultivo de fibroblastos fue incubado durante $48 \mathrm{~h}$ con los diferentes tratamientos (extracto, proteína K1, proteína K2). Se observó en el grupo control (sin tratamiento) que pocos fibroblastos migraron al sitio de la herida, además la monocapa no fue restaurada en su totalidad (Figura 4). 
log dosis vs \% proliferación-24 horas

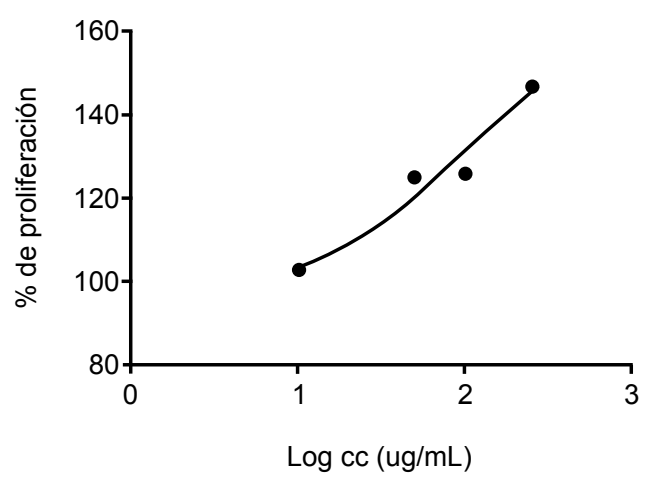

log dosis vs \% proliferación-48 horas

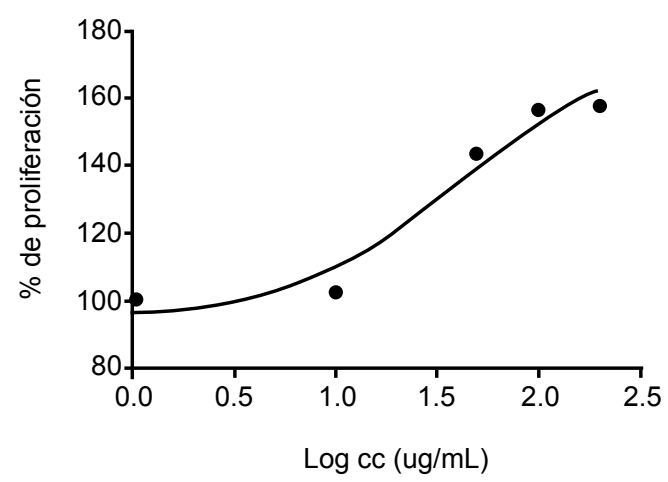

Figura 3. Gráficas Logarítmicas (log) de la concentración de extracto vs el porcentaje de proliferación a las 24 y 48 horas respectivamente

Las diferentes dosis del extracto $(50,100$ y $200 \mu \mathrm{g} / \mathrm{mL})$ no causaron un efecto citotóxico sobre la monocapa de fibroblastos, sin embargo, se observó un aumento en la migración con respecto al control. El cultivo tratado con $200 \mu \mathrm{g} / \mathrm{mL}$ del extracto hidroetanólico después de $48 \mathrm{~h}$ de incubación, mostró un aumento significativo con respecto a los demás controles (Figura 6A). Así mismo, se evaluó el efecto de las proteínas $\mathrm{K} 1$ y K2 (10 y $50 \mu \mathrm{g} / \mathrm{mL}$ ) en la monocapa de fibroblastos. Se evaluaron las distancias de migración celular a las 24 y $48 \mathrm{~h}$ después de aplicados los tratamientos. La migración de fibroblastos hacia la herida inducida se cuantificó utilizando el software de análisis de imágenes Win Scratch, el cual proporcionó los porcentajes de migración respectivos (Figura 5).

\section{ANÁLISIS DE EXPRESIÓNDEADNc MEDIANTE RT-qPCR}

Se realizó la cuantificación relativa con el método de $2^{\Delta \Delta C t}$, utilizando el gen de referencia: gliceraldehído 3-P-deshidrogenasa GAPDH ${ }^{(17)}$. Se trabajó por triplicado y se observó diferencias altamente significativas en los patrones de expresión respecto al control (Figura 6). Se observó un incremento significativo de la expresión del gen PDGF; después de una hora de incubación con los tratamientos (extracto, proteína K1 y proteína K2), hubo diferencias altamente significativas en la expresión relativa de PDGF, ocho veces mayor respecto al control; con la proteína K2 $(100 \mu \mathrm{g} / \mathrm{mL})$. La proteína K1 (100 $\mu \mathrm{g} / \mathrm{mL}$ ) aumentó la expresión de PDGF en 4,5 veces (Figura 6A). Hubo diferencias altamente significativas en la expresión de FGF, al ser tratado con el extracto $(200 \mu \mathrm{g} / \mathrm{mL}$ ); después de $3 \mathrm{~h}$ de incubación (Figura 6D).

\section{DISCUSIÓN}

Estudios previos detallan que Piper aduncum, posee efecto cicatrizante; sin embargo, la actividad del extracto no fue evaluada in vitro; considerando que el proceso de cicatrizacion involucra diversas etapas en las que interactúan poblaciones celulares y factores de crecimiento ${ }^{(17)}$.

Existe informacion a cerca de la composición del extracto
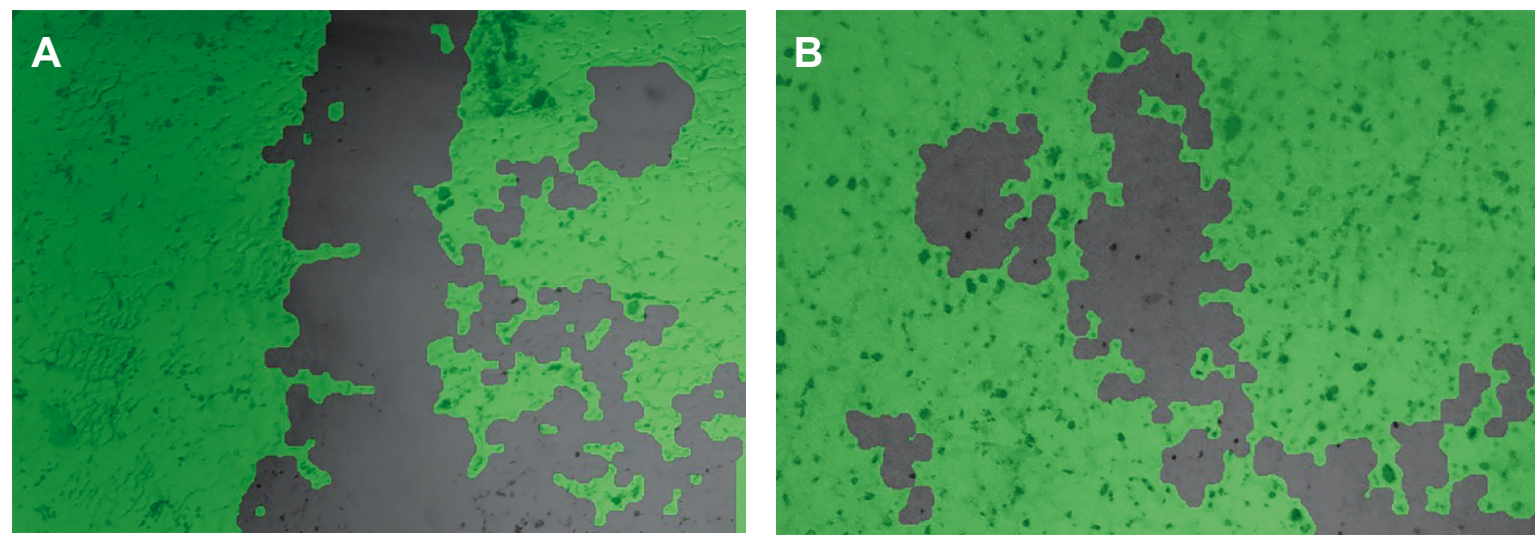

Figura 4. A. Se observa la monocapa de fibroblastos después de $24 \mathrm{~h}$ de incubación sin tratamiento. B. Monocapa de fibroblastos después de $24 \mathrm{~h}$ con $200 \mu \mathrm{g} / \mathrm{mL}$ del extracto hidroetanólico 
de Piper aduncum (terpenos, alcaloides, flavonoides); sin embargo, no se relizó un estudio que permita aislar e identificar proteinas o péptidos como potenciales compuestos bioactivos. Por estas razones, en este trabajo se evaluó el efecto del extracto y proteínas purificadas sobre la migración, proliferación y expresión relativa de factores de crecimiento en cultivo celular de fibroblastos (hDFa) ${ }^{(10,12)}$.

Las cinco proteinas identificadas mediante RP-HPLC poseen un dominio en común ampliamente conservado, el cual pertenece a la superfamilia "STI" de tipo Kunitz (inhibidores de tripsina), los cuales son inhibidores de proteasas. Las proteinas de la familia Kunitz; se unen con alta afinidad a sitios activos de proteasas y poseen un plegamiento característico, el cual fue encontrado también en factores de crecimiento (FGF) e interleuquinas (IL-1 $\beta$ ). Las proteasas en situaciones de herida ocasionan la degradación de la matriz extracelular (ME) y de otras proteinas como factores de crecimiento; en consecuencia, se produce una prolongación de la fase inflamatoria, lo que impide que la herida avance hacia la fase proliferativa. Por estas razones, las proteínas que se encuentran en el extracto hidroetanolico de Piper aduncum podrían favorecer el proceso de cicatrización, al tener actividad inhibitoria sobre proteasas ${ }^{(18-21)}$.

Durante la formacion de tejido de granulación en una herida, se liberan factores de crecimiento para estimular la migración y proliferación de fibroblastos al sitio de la herida. El extracto hidroetanolico de Piper aduncum aumentó significativamente la migracion y proliferacion de fibroblastos en cultivo; comparado a un control no tratado. En ambos ensayos se observó un efecto dosisdependiente para los tratamientos (extracto, proteina $\mathrm{K} 1$, proteina $\mathrm{K} 2$ ), considerando $24 \mathrm{~h}$ de incubación. La proteína K2 (1ug/mL),incrementó de manera significativa la proliferación de fibroblastos, sin embargo a medida que se incrementó la dosis se observó una disminución en la proliferación, este efecto podría darse por el aumento de la confluencia en los pozos de cultivo celular o por un efecto citotóxico de la proteína en el cultivo. (Figura 2B)

Así mismo, cuando se considera 48 y 72 h de incubación, se observó un efecto citotóxico en la proliferacion celular, por tal motivo, para posteriores ensayos se recomienda determinar el valor de $\mathrm{IC}_{50}$ de ambas proteínas ${ }^{(22)}$.

En el ensayo de migración celular (técnica del rayado), para todos los casos, se observó un efecto dosis dependiente. La proteina $\mathrm{K} 2(50 \mu \mathrm{g} / \mathrm{mL})$ tuvo un efecto altamente significativo en la migración. La técnica del rayado presenta algunas ventajas por ser sencilla, rápida y fácil de interpretar; sin embargo, se debe tomar en cuenta algunos inconvenientes como si existen variaciones en el ancho de la herida inducida; siendo este parámetro crítico en la evaluación de la migración de fibroblastos. Además, algunas células permanecen adheridas en la placa después de la inducción de la herida. Por estos motivos se recomieda utilizar nuevas técnicas que no presenten variación significativa en el tamaño de la herida, una

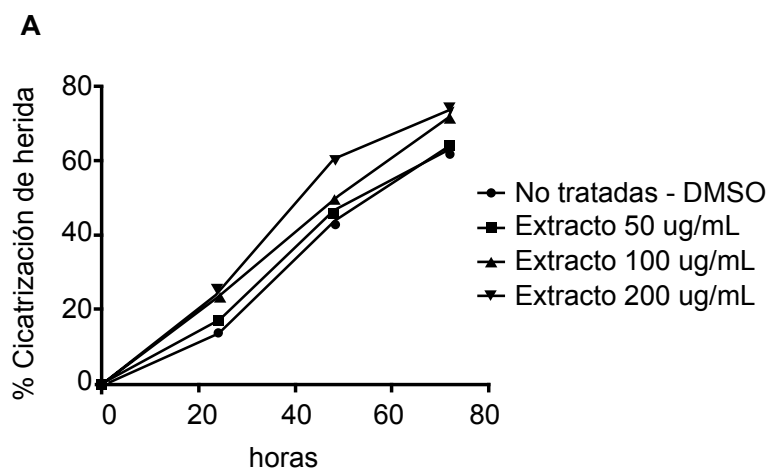

B

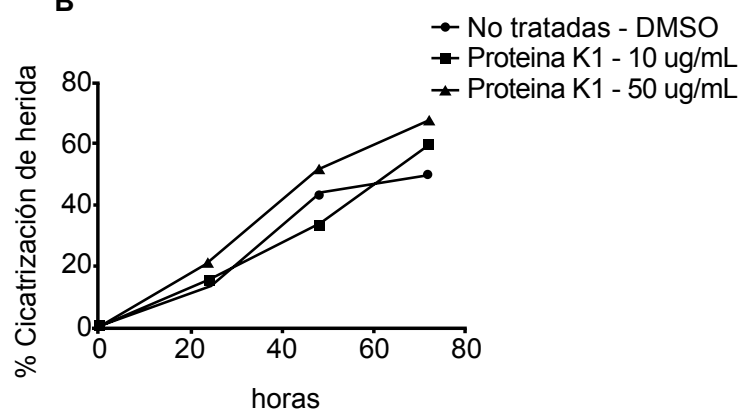

C

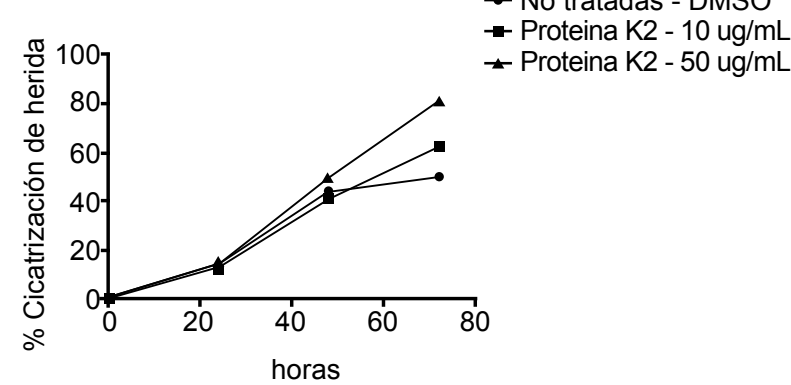

Figura 5. Migración de fibroblastos después de 24, 48 y 72 h de incubación, utilizando la "técnica del rallado"(Scratch). A. Porcentaje de cicatrización de herida (migración) con el extracto hidroetanólico (50,100 y $200 \mu \mathrm{g} / \mathrm{mL})$. B. Porcentaje de cicatrización de herida (migración) con proteína K1 (10 y $50 \mu \mathrm{g} / \mathrm{mL})$ C. Porcentaje de cicatrización de herida con proteína K2 (10 y $50 \mu \mathrm{g} / \mathrm{mL}$ ) 
de estas técnicas es ECIS (detección de la impedancia eléctrica de la célula-sustrato) ${ }^{(23)}$.

Por otro parte en el presente estudio se utilizó la prueba de RT-qPCR en tiempo real para evaluar los efectos del extracto acuoetanolico de Piper aduncum y las proteinas $\mathrm{K} 1$ y K2 en los niveles de expresión de los genes FGF, EGF Y PDGF. Los datos obtenidos demostraron que los tratamientos (extracto, proteína $\mathrm{K} 1$, proteína $\mathrm{K} 2$ ) aumentaron significativamente la expresion génica de PDGF, FGF Y EGF. Sin embargo, el efecto de las proteínas $\mathrm{K} 1$ y $\mathrm{K} 2$ en la expresion, después de $3 \mathrm{~h}$ tuvo un aumento altamente significativo comparado al efecto del extracto. En este ensayo se utilizó el gen GAPDH como referencia; sin embargo, para posteriores ensayos se recomienda utilizar otros genes, ya que algunos trabajos describen que la expresión de GAPDH es alterada en el proceso de cicatrización ${ }^{(24)}$.

Los efectos sinérgicos de las mezclas de componentes bioactivos contenidos en extractos de plantas pueden explicar su importancia ${ }^{25)}$. Por tal motivo, en este estudio se demostró que el extracto hidroetanólico de Piper aduncum aumentó la proliferación, migración de fibroblastos humanos, e incrementó la expresión de los genes FGF, EGF y PDGF; eventos que demuestran su efecto cicatrizante.

Sin embargo, los resultados más resaltantes ponen en
A

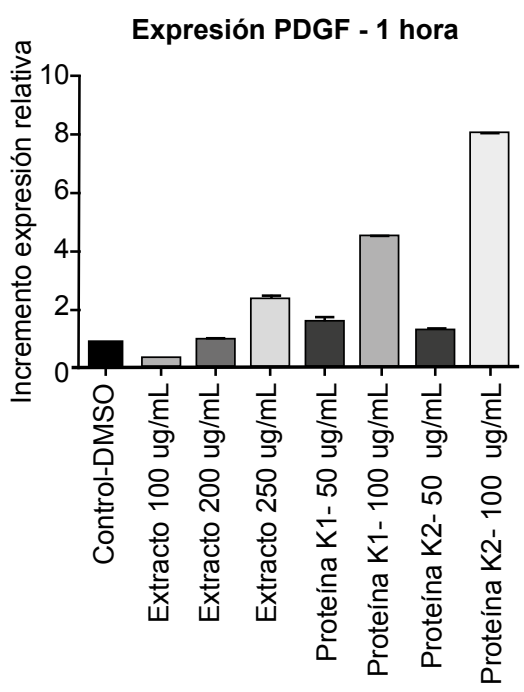

B

Expresión PDGF - 3 horas

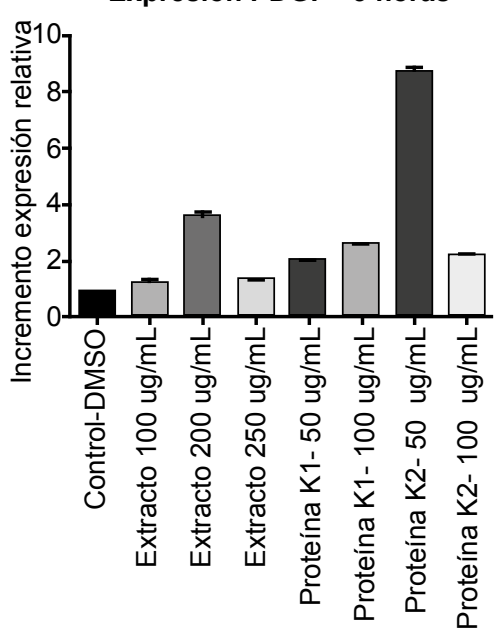

C

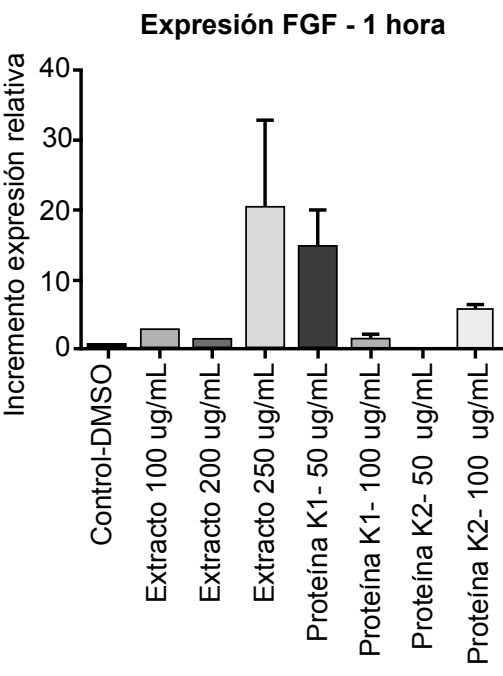

D

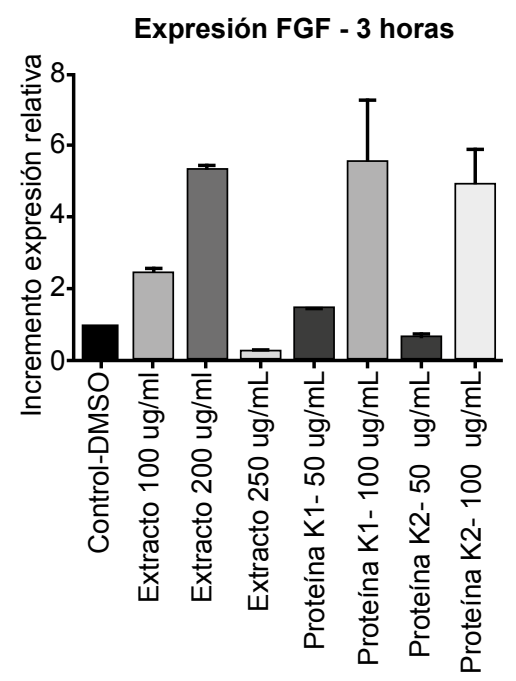

E

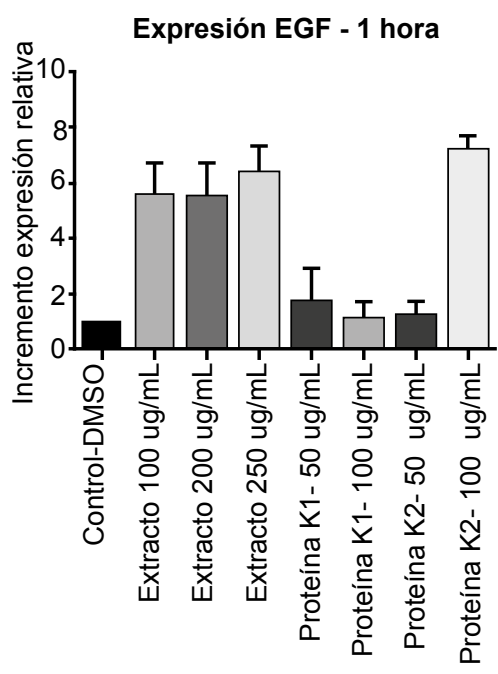

$\mathbf{F}$

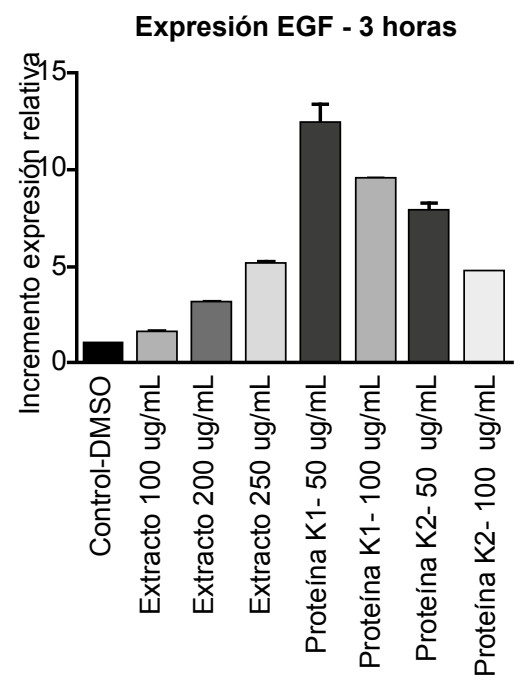

Figura 6. (A y B) Incremento de la expresión relativa de PDGF después de 1 y $3 \mathrm{~h}$ respectivamente. (C y D) Incremento de la expresión relativa de FGF después de 1 y 3 h respectivamente. (E y F) Incremento de la expresión relativa de EGF después de 1 y 3 $\mathrm{h}$ respectivamente. Las barras indican diferencias altamente significativas $p<0,05$ comparadas con el control 
evidencia que las proteinas $\mathrm{K} 1$ y $\mathrm{K} 2$ tienen efecto potencial en la cicatrización, se obtuvieron diferencias altamente significativas comparadas a los controles. Estos resultados respaldan la hipótesis de que péptidos activos y proteínas derivadas de plantas tienen efectos beneficiosos en la salud humana, en este caso, en el proceso de cicatrización ${ }^{(7,26)}$.

La identificacion de péptidos bioactivos a partir de extractos de plantas es clave para el diseño de nuevas terapias para la curacion de heridas agudas y crónicas. En un futuro, la combinación de varios péptidos permitirá desarrollar una nueva clase de terapia que tenga implicancias en la cicatrización ${ }^{(27)}$.

Futuras investigaciones deberán establecer los mecanismos de actividad de los péptidos y se podrá demostrar que pueden estimular respuestas celulares en lesiones in vivo. Finalmente, la investigación de plantas nativas, extractos, o fracciones proteicas aun es incipiente, por lo que se convierte en un área de interés para futuras investigaciones.

Contribuciones de autoría: KP, LAPS, MLI y JLA participaron en el diseño, recopilación, análisis, interpretación de datos y redacción del artículo, además de su revisión crítica y aprobación de la versión final.

\section{Fuente de financiamiento: autofinanciado}

Conflictos de interés: los autores declaran no tener conflictos de interés.

\section{REFERENCIAS BIBLIOGRÁFICAS}

1 Dorvigny BM, Sánchez LM, Diaz $S$, Bulnes C, Ivis A, Escobar A, et al. Efecto cicatrizante de la pasta de clorofilacaroteno de Pinus caribaea var. caribaea sobre heridas abiertas asépticas. Rev Cuba Plantas Med. 2011;16(1):24-33.

2 Velnar T, Bailey T, Smrkolj V. The wound healing process: an overview of the cellular and molecular mechanisms. J Int Med Res. 2009;37(5):1528-42.

3. Barrientos $\mathrm{S}$, Stojadinovic $\mathrm{O}$, Golinko MS, Brem H, Tomic-Canic M. Growth factors and cytokines in wound healing. Wound Repair Regen. 2008;16(5):585-601. doi: 10.1111/j.1524-475X.2008.00410.x.

4. Valencia C. Cicatrización: Proceso de reparación tisular, aproximaciones terapeúticas. Investigaciones Andina. 2010;12(20):85-98.

5. Thakur R, Jain N, Pathak R, Sandhu SS. Practices in wound healing studies of plants. Evid Based Complement Alternat Med. 2011;2011:43056. doi: $10.1155 / 2011 / 438056$.

6. Malaguti M, Dinelli G, Leoncini E, Bregola V, Bosi S, Cicero AF, et al. Bioactive peptides in cereals and legumes: agronomical, biochemical and clinical aspects. Int $\mathrm{J}$ Mol Sci. 2014; 15(11):21120-21135; doi: 10.3390/ijms151121120.

7. Sharma S, Verma HN, Sharma NK. Cationic bioactive peptide from the seeds of Benincasa hispida. Int J Pept. 2014;2014:156060. doi: $10.1155 / 2014 / 156060$

8. Taylor L. Technical data Report for Matico (Piper aduncum, angustifolium). Carson City: RAINTREE; 2006
9. Guerrini A, Sacchetti G, Rossi D, Paganetto G, Muzzoli M, Andreotti E, et al. Bioactivities of Piper aduncum L. and Piper obliquum Ruiz \& Pavon (Piperaceae) essential oils from Eastern Ecuador. Environ Toxicol Pharmacol. 2009;27(1):39-48. doi: 10.1016/j. etap.2008.08.002

10. Arroyo J, Hañari R, Tinco A, Baca D, Domínguez L, Buendía J, et al. Efecto antihipertensivo del extracto de Piper aduncum "matico" sobre la hipertensión inducida por L-NAME en ratones. An Fac med. 2012;73(4):275-80.

11. Aguilar M. Reversed-Phase HighPerformance Liquid Chromatography. In: HPLC of peptides and proteins: Methods and protocols. Volume 251 of the series Methods in Molecular Biology $\mathrm{y}^{\text {rux }}$. Springer: London; 2004. pp. 9-23.

12. Abián J, Carrascal M, Gay M. Introducción a la Espectrometría de masas para la caracterización de péptidos y proteínas en proteómica. Proteómica. 2008;2:16-35.

13. Mosmann T. Rapid colorimetric assay for cellular growth and survival: Application to proliferation and cytotoxicity assays. J Immunol Methods. 1983;65(1-2):55-63.

14. Liang CC, Park AY, Guan JL. In vitro scratch assay: a convenient and inexpensive method for analysis of cell migration in vitro. Nat Protoc. 2007;2(2):329-33.

15. Fronza M, Heinzmann B, Hamburger M, Laufer S, Merfort I. Determination of the wound healing effect of Calendula extracts using the scratch assay with
3T3 fibroblasts. J Ethnopharmacol. 2009;126(3):463-7. doi: 10.1016/j. jep.2009.09.014.

16. Livak KJ, Schmittgen TD. Analysis of Relative Gene Expression Data Using Real-Time Quantitative PCR and the $2-\Delta \Delta \mathrm{CT}$ Method. Methods. 2001;25(4):402-8.

17. Zimic Z, Viñas $S$, Zavalaga Z, Villegas $S$, Cardozo Z, Evangelista CE. Healing effect study of Piper angustifolium R \& $\mathrm{P}$ "matico" on induced lessions in diabetic mice. Forjando. Resumenes de Investigaciones. 2013;1(1):61.

18. Onesti S, Brick P, Blow DM. Crystal structure of a Kunitz-type trypsin inhibotr drom Erythrina caffra seeds. J Mol Biol. 1991;217(1):153-76.

19. Murzin AG, Lesk AM., Chothia C. B-Trefoil fold: Patterns of Structure and Sequence in th Kunitz Inhibitors Interleukins $-1 \beta$ and $1 \alpha$ and Fibroblast Growth Factors. J Mol Biol. 1992;223(2):531-43.

20. Consenso internacional. Función de las proteasas en el diagnóstico de heridas. Revisión de un grupo de trabajo de expertos. Londres: Wounds International; 2011.

21. Rawlings ND, Tolle DP, Barrett AJ. Evolutionary families of peptidase inhibitors. Biochem J. 2004;378(Pt 3):705-16.

22. Schreier T, Degen E, Baschong W. Fibroblast migration and proliferation during in vitro wound healing. A quantitative comparison between various growth factors and a low molecular weight blood dialysate used in the clinic to normalize impaired 
wound healing. Res Exp Med (Berl). 1993;193(4):195-205.

23. N. Kramer, Walzl A, Unger C, Rosner M, Krupitza G, Hengstschläger M, et al. In vitro cell migration and invasion assays. Mutat Res. 2013;752(1):10-24. doi: 10.1016/j.mrrev.2012.08.001.

24. Turabelidze A, Guo S, DiPietro LA. Importance of housekeeping gene selection for accurate RT- qPCR in a wound healing model. Wound Repair Regen. 2010;18(5):460-6. doi: 10.1111/j.1524-475X.2010.00611.x.
25. Wagne Hr, Ulrich-Merzenich G. Synergy research: Approaching a new generation of phytopharmaceuticals. Phytomedicine. 2009; 16(2-3):97-110. doi:10.1016/j.phymed.2008.12.018.

26. Homayouni-Taabrizi M, Asoodeh A, Abbaszadegan MR, Shahrokhabadi K, Nakhaie Moqhaddam M. An identified antioxidant peptide obtained from ostrich (Struthio camelus) egg white protein hydrolysate shows wound healing properties. Pharm Biol. 2015;53(8):1155-62. doi: $10.3109 / 13880209.2014 .962061$.
27. Demidova-Rice TN, Geevarghese A, Herman IM. Bioactive peptides derived from vascular endotelial cell extracelular matrices promote microvascular morphogenesis and wound healing in vitro. Wound Repair Regen. 2011;19(1):59-70. doi:10.1111/ j.1524-475X.2010.00642.x.

Correspondencia: Karen Paco

Dirección: Calle Roma 350, Dpto 302. San Isidro. Lima, Perú

Teléfono: (+511) 945050647

Correo Electrónico: karen.paco.m@upch.pe

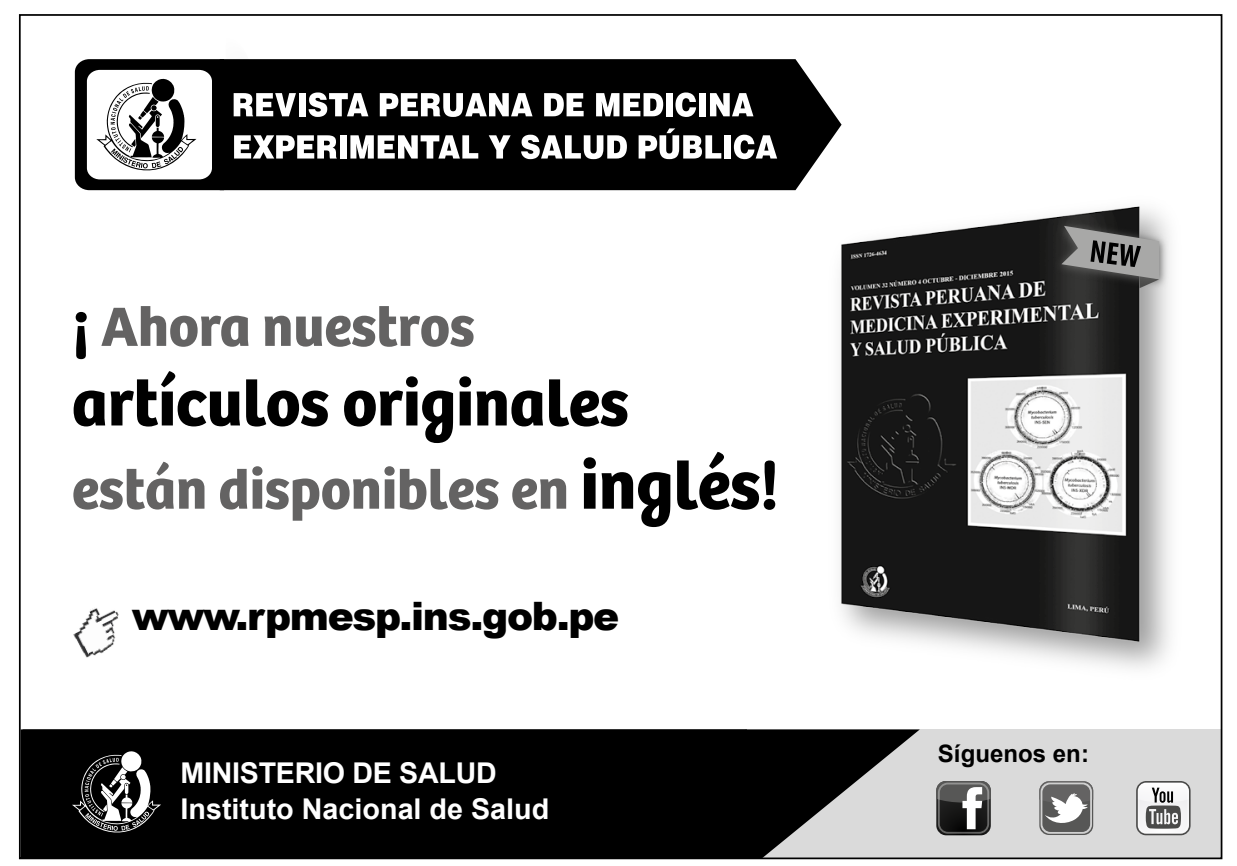

